\title{
FATIGUE LIFE ESTIMATION MODELS: A STATE OF THE ART
}

\author{
M. Kamal ${ }^{1}$ and M.M. Rahman ${ }^{1,2^{*}}$ \\ ${ }^{1}$ Faculty of Mechanical Engineering, Universiti Malaysia Pahang \\ 26600 Pekan, Pahang, Malaysia \\ *Email: mustafizur@ump.edu.my \\ Phone: +6094262239; Fax: +6094246222 \\ ${ }^{2}$ Automotive Engineering Centre, Universiti Malaysia Pahang \\ 26600 Pekan, Pahang, Malaysia \\ ${ }^{3}$ Faculty of Manufacturing Engineering, Universiti Malaysia Pahang \\ 26600 Pekan, Pahang, Malaysia
}

\begin{abstract}
In this paper, a state of the art of recently proposed fatigue prediction models has been conducted. The modified Wöhler curve method (MWCM) with a critical plane model utilizing the maximum variance method (MVM), and an endurance function model utilizing a stress invariant are studied for fatigue life evaluation. The results are compared with experimental results as well as results from already established fatigue models using a fatigue life estimation tool. The study shows that new models have good accuracy that is approximately the same as for the established models, and are easy to apply in various conditions like multiaxial and variable amplitude loading conditions, which is a limitation of the older models. It is concluded that the newly formulated models are a promising development and should be studied in detail to make their application simpler with complex real-world problems.
\end{abstract}

Keywords: Maximum variance method; modified Wöhler curve method; endurance function; stress invariants; fatigue life.

\section{INTRODUCTION}

Many automotive industrial components including suspension arms, connecting rods, and train suspension springs contain defects of different sizes and geometries (AlAsady, Abdullah, Ariffin, Bedan, \& Rahman, 2009; Kamal, Rahman, \& Rahman, 2012; Rahman, Ariffin, Jamaludin, \& Haron, 2007; Rahman, Ariffin, Rejab, Kadirgama, \& Noor, 2009b; Rahman, Noor, Kadirgama, Maleque, \& Bakar, 2011). Some of these components are classified as safety components and thus they have to be subjected to particular attention during fatigue design in order to guarantee an appropriate in-service durability with light-weight design (Abdullah, Beden, Ariffin, \& Rahman, 2008; Kamal, Rahman, \& Sani, 2013; Rahman et al., 2008; Rahman, Ariffin, Jamaludin, \& Haron, 2006). Hence, the problem of high-cycle fatigue life estimation of components containing defects is of great importance from a social, scientific and industrial point of view (Rahman, Ariffin, Jamaludin, \& Haron, 2005; Rahman et al., 2007; Rahman, Ariffin, Rejab, Kadirgama, \& Noor, 2009c). The fatigue process of mechanical components under service loading is variable amplitude in nature (Bedan, Abdullah, Ariffin, Al-Asady, \& Rahman, 2008; Rahman et al., 2006, 2007). Life 
prediction and durability assessment is still a challenging problem that has been extensively studied in the past decades (Abdullah, Al-Asady, Ariffin, \& Rahman, 2008; Rahman, Ariffin, Abdullah, Noor, \& Bakar, 2009a; Rahman et al., 2006, 2007). Many critical mechanical components experience cyclic loadings during their service life. By contrast with the uniaxial fatigue problem, the multiaxial fatigue problem is more involved due to the complex stress states, loading histories and different orientations of the fatigue crack in the components.

The first proposed models for fatigue life calculations under a triaxial random stress state were formulated in the 1970s (Macha \& Niesłony, 2007). They were based on generalization of known models applied for cyclic loadings. These models included: (i) an assumption of the shear and normal stresses on the critical planes of fatigue fracture as quantities strongly influencing the failure; (ii) changes of the principal stresses and strains; and (iii) their conformity (in special cases) with the known and verified models applied under cyclic loadings (Ali, Mustapa, Ghazali, Sujitno, \& Ridha, 2013; Macha \& Niesłony, 2007; Stephens, Fatemi, Stephens, \& Fuchs, 2000). There are also strain and energy models in which, as in the stress models, the equivalent histories of strains and the energy parameter are calculated according to the assumed criterion of multiaxial fatigue failure (Hariharan, Prakash, \& Prasad, 2011; Lagoda, Macha, \& Bedkowski, 1999; Rahman et al., 2009c). These models for calculation of the fatigue life of materials and structures belong to the group of algorithmic methods, where loading histories are analyzed in the time domain with the numerical algorithms of cycle counting (Domínguez Almaraz, Guzmán Tapia, Tapia Silva, \& Cadenas Calderón, 2010; Meggiolaro \& de Castro, 2012). Another group of models, using the so-called spectral method, applied spectral analysis of stochastic processes during fatigue life assessment (Macha \& Niesłony, 2007).

Multiaxial loads, which can be in-phase (proportional) or out-of-phase (nonproportional), are common for many components and structures (Rahman et al., 2009b). Even under uniaxial loads, multiaxial stresses often exist, although typically inphase, due to geometric constraints at notches. Such multiaxial loads and stress states are frequently encountered in many industries, including automotive, aerospace, and power generation (Rahman et al., 2005, 2007; Rahman et al., 2009c). Many scientific centers and researchers are dealing with this issue, conducting new tests and developing models for the description of fatigue phenomena; however, no universal solution has yet been found (Papuga, 2011). In this paper, two recently proposed models have been studied, the first being the modified Wöhler curve method (MWCM) (Susmel \& Taylor, 2008) in conjunction with the theory of critical distances (TCD) used in the form of the point method (Laurens, Koolwijk, \& De Maat, 2006; Susmel, 2010). To apply MWCM, the critical plane is determined by the maximum variance method (MVM) (Susmel, 2010; Susmel \& Taylor, 2008). The second is the endurance function model based on stress invariants and continuum damage mechanics formulation (Borlea, Rusu, Ionescu, Cretu, \& Ionescu, 2011; Ottosen, Stenstrom, \& Ristinmaa, 2008). The model does not require any evaluation of a critical plane as the model considers the damage accumulated at a point using stress tensor invariants and deviatoric stress invariants (Brighenti, Carpinteri, \& Vantadori, 2006). A genetic algorithm (GA) approach is employed to evaluate numerically the several parameters used for characterization of the damage mechanics approach, once the effects of some experimental complex histories are known (Brighenti et al., 2006). 


\section{FINITE ELEMENT ANALYSIS}

Finite element analysis (FEA) is performed on specimen geometry which is used in determining experimentally the fatigue life of steel alloy $\mathrm{C} 40$ published in literature (Bedan et al., 2008) shown in Figure 1(a). The three-dimensional model is design using computer aided software and the finite element model is developed utilizing the ANSYS software with 10-node tetrahedral elements, to better capture the curved surfaces of the specimen geometry. Dense mesh at the notch root is maintained by the sphere of influence technique. Loads are applied in the form of normal and shear stress at the net area, in-phase and out-of-phase loading conditions are considered, and corresponding force and moment and fixed support constraints are applied on the specimen model, as shown in Figure 1 (c). The detail of the applied loads and respective fatigue life, taken from the literature (Atzori, Berto, Lazzarin, \& Quaresimin, 2006), is reported in Table 1. The notch root is considered to be the critical point for crack initiation and to predict the fatigue life as close to the experimental values as possible, and the state of stress at the notch root is used in estimation of the fatigue life.

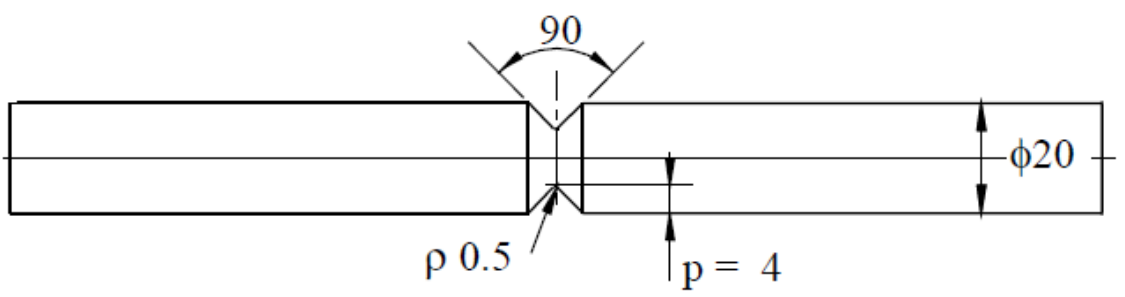

(a) Dimensions of specimen (Atzori et al., 2006)

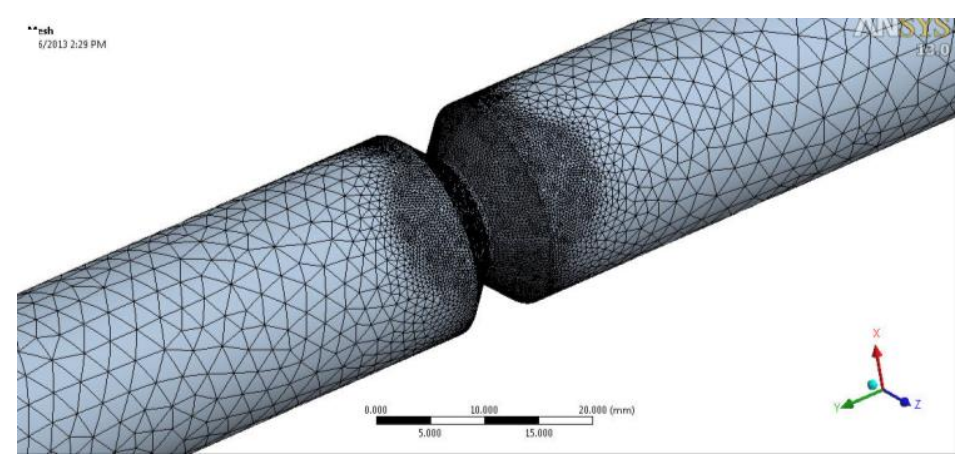

(b) FEA model

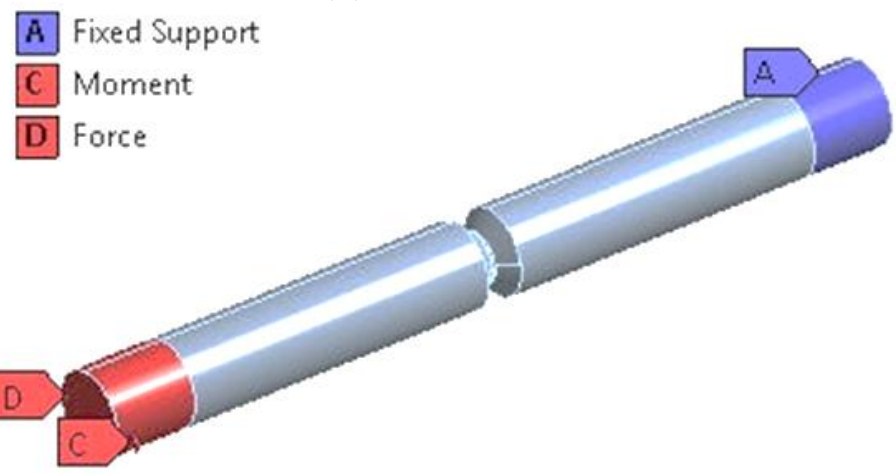

(c) Applied loads on specimen

Figure 1. C40 test specimen and FEA model. 
Table 1. Experimental loads and fatigue life of $\mathrm{C} 40$ specimen having notch radius $0.5 \mathrm{~mm}$ (Atzori et al., 2006).

\begin{tabular}{ccccc}
\hline $\begin{array}{c}\text { Normal stress } \\
\text { at net area } \sigma_{\mathrm{a}} \\
(\mathrm{MPa})\end{array}$ & $\begin{array}{c}\text { Shear stress } \\
\text { at net area } \tau_{\mathrm{a}} \\
(\mathrm{MPa})\end{array}$ & $\begin{array}{c}\text { Load ratio } \\
(\mathrm{R})\end{array}$ & $\begin{array}{c}\text { Phase } \\
\text { difference }\left({ }^{\circ}\right)\end{array}$ & $\begin{array}{c}\text { Cycles to } \\
\text { failure }\left(\mathrm{N}_{\mathrm{f}}\right) \\
\times 10^{6}\end{array}$ \\
\hline 200.00 & 200.00 & -1 & 0 & 0.027 \\
179.00 & 179.00 & -1 & 0 & 0.220 \\
160.00 & 160.00 & -1 & 0 & 0.072 \\
129.75 & 129.75 & -1 & 0 & 0.180 \\
118.80 & 118.80 & -1 & 0 & 0.440 \\
101.00 & 101.00 & -1 & 0 & 2.000 \\
199.70 & 199.70 & -1 & 90 & 0.011 \\
180.00 & 180.00 & -1 & 90 & 0.018 \\
160.25 & 160.25 & -1 & 90 & 0.047 \\
140.00 & 140.00 & -1 & 90 & 0.280 \\
129.65 & 129.65 & -1 & 90 & 0.690 \\
99.60 & 99.60 & -1 & 90 & 2.000 \\
\hline
\end{tabular}

\section{RESULTS AND DISCUSSION}

\section{Mesh Convergence Study}

A study for mesh convergence of the finite element analysis (FEA) model was performed to get the optimum mesh size which gives a good balance between accuracy and processor time and storage load (Rahman et al., 2009a; Rahman, Kadirgama, Noor, Rejab, \& Kesulai, 2009d). Maximum principal, von Mises and Tresca stresses are monitored for mesh convergence with acceptable processing load. Figure 2 shows the result of the mesh sensitivity analysis. It can be seen that after a mesh size of $0.175 \mathrm{~mm}$, the values of the stresses do not change by any appreciable amount, but there is an exponential rise in the number of nodes and elements, which will result in an increase of processor time and storage requirement without much increase in the accuracy of the stress results. Hence, to get the optimum performance, a mesh size of $0.175 \mathrm{~mm}$ is selected for meshing both specimen models.

\section{MWCM with MVM and TCD}

MWCM postulates that fatigue damage depends on the maximum shear stress amplitude $\left(\tau_{a}\right)$ as well as on the mean value $\left(\sigma_{n, m}\right)$ and the amplitude $\left(\sigma_{n, a}\right)$ of the normal stress relative to that plane experiencing the maximum shear stress amplitude (i.e., the socalled critical plane) (Susmel \& Taylor, 2008). In particular, the MWCM assumes that fatigue strength can be directly estimated through the amplitude of the shear stress relative to the critical plane $\left(\tau_{a}\right)$ provided that the adopted reference fatigue curve is defined by fully taking into account, by means of ratio $\left(\rho_{\text {eff }}\right)$, the actual degree of multiaxiality of the stress field damaging the fatigue process zone (Susmel, 2010; Susmel \& Taylor, 2008). The degree of multiaxiality is taken into account by means of ratio $\rho_{\text {eff }}$, i.e., the effective value of the critical plane stress ratio in Eq. (1): 


$$
\rho_{\text {eff }}=\frac{m \sigma_{n, m}+\sigma_{n, a}}{\tau_{a}}
$$

where $m$ is the mean stress sensitivity index, i.e., a material constant ranging between 0 and 1 and giving a measure of the material sensitivity to nonzero mean stresses perpendicular to the critical planes. Calibration functions are defined as (Susmel, 2010; Susmel \& Taylor, 2008):

$$
\begin{aligned}
& k_{\tau}(e f f)=a \rho_{e f f}+b \\
& \tau_{A, \operatorname{Re} f f}(e f f)=\alpha \rho_{e f f}+\beta
\end{aligned}
$$

where $a, b, \alpha$ and $\beta$ are fatigue constants to be determined experimentally.

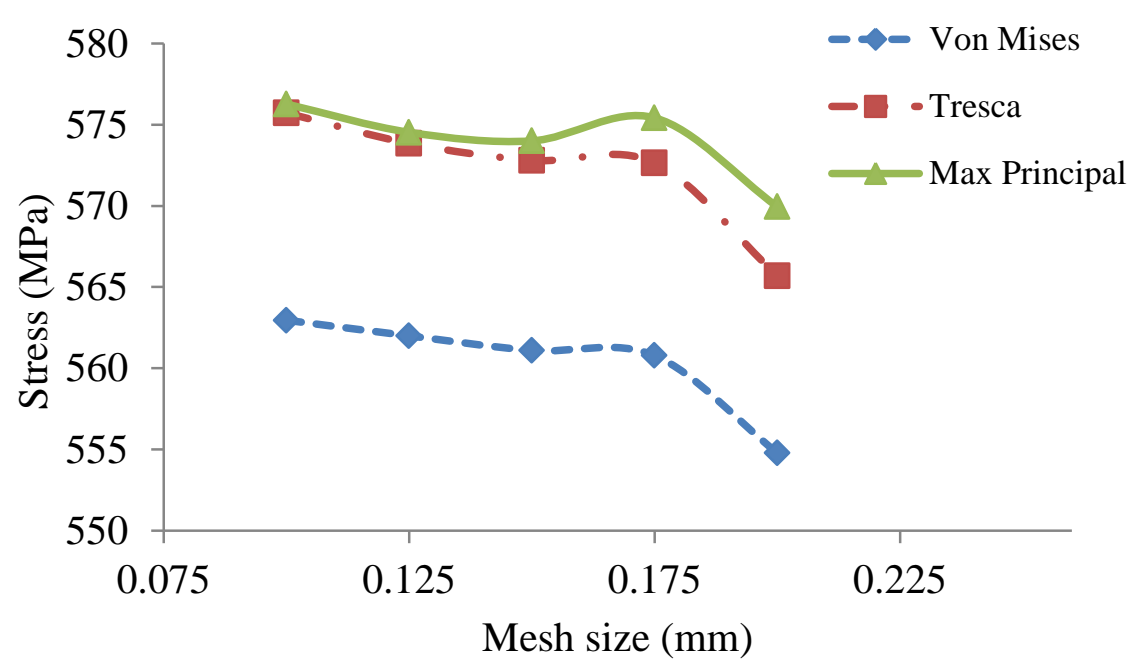

(a)

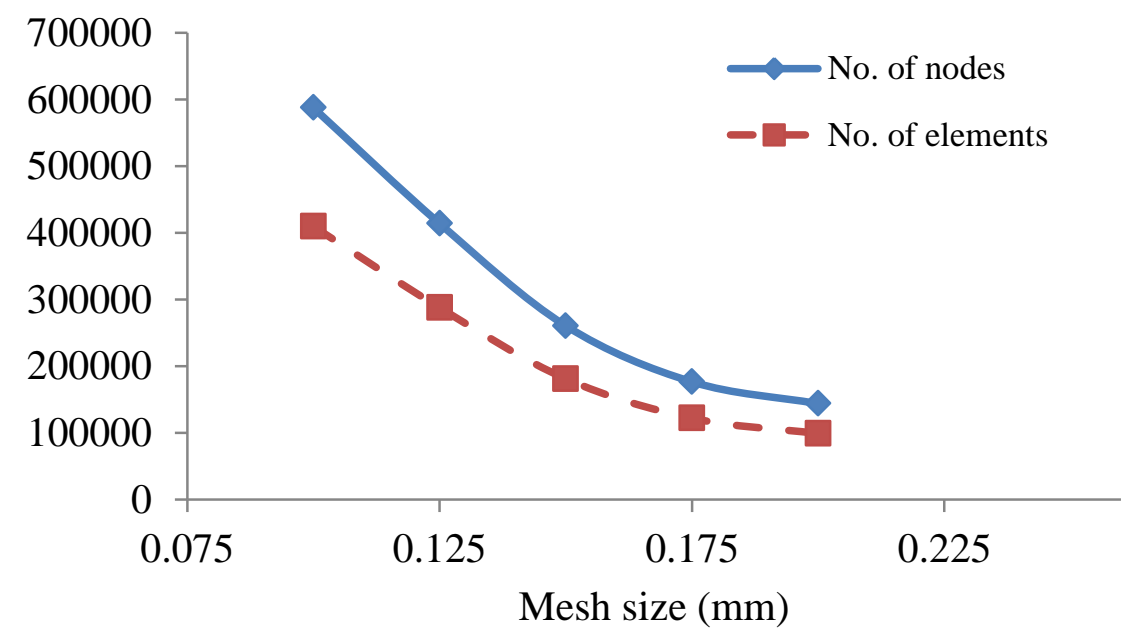

(b)

Figure 2. (a) Mesh size versus calculated FEA stresses, (b) Mesh size versus no. of nodes and elements of FEA model. 
The linear-elastic TCD takes the assumption that the critical distance value to be used to calculate an effective equivalent stress is a material property whose value increases with decreasing of the number of cycles to failure (Susmel, 2010; Susmel \& Taylor, 2008).

$$
L_{M}\left(N_{f}\right)=A \cdot N_{f}^{B}
$$

The MVM assumes that fatigue damage is proportional to the variance of the stress signal that is damaging, at the assumed critical point, the component being assessed. A critical plane is identified from planes with maximum variance in shear stress, from which selected planes the critical plane is identified as the one with maximum $\rho_{\text {eff. }}$ To estimate fatigue life, the following methodology is highlighted in Figure 3, where the values of $\tau_{a}(r), \sigma_{n, a}(r), \sigma_{n, m}(r)$, are calculated at the critical plane identified by MVM at distance ' $r$ '.

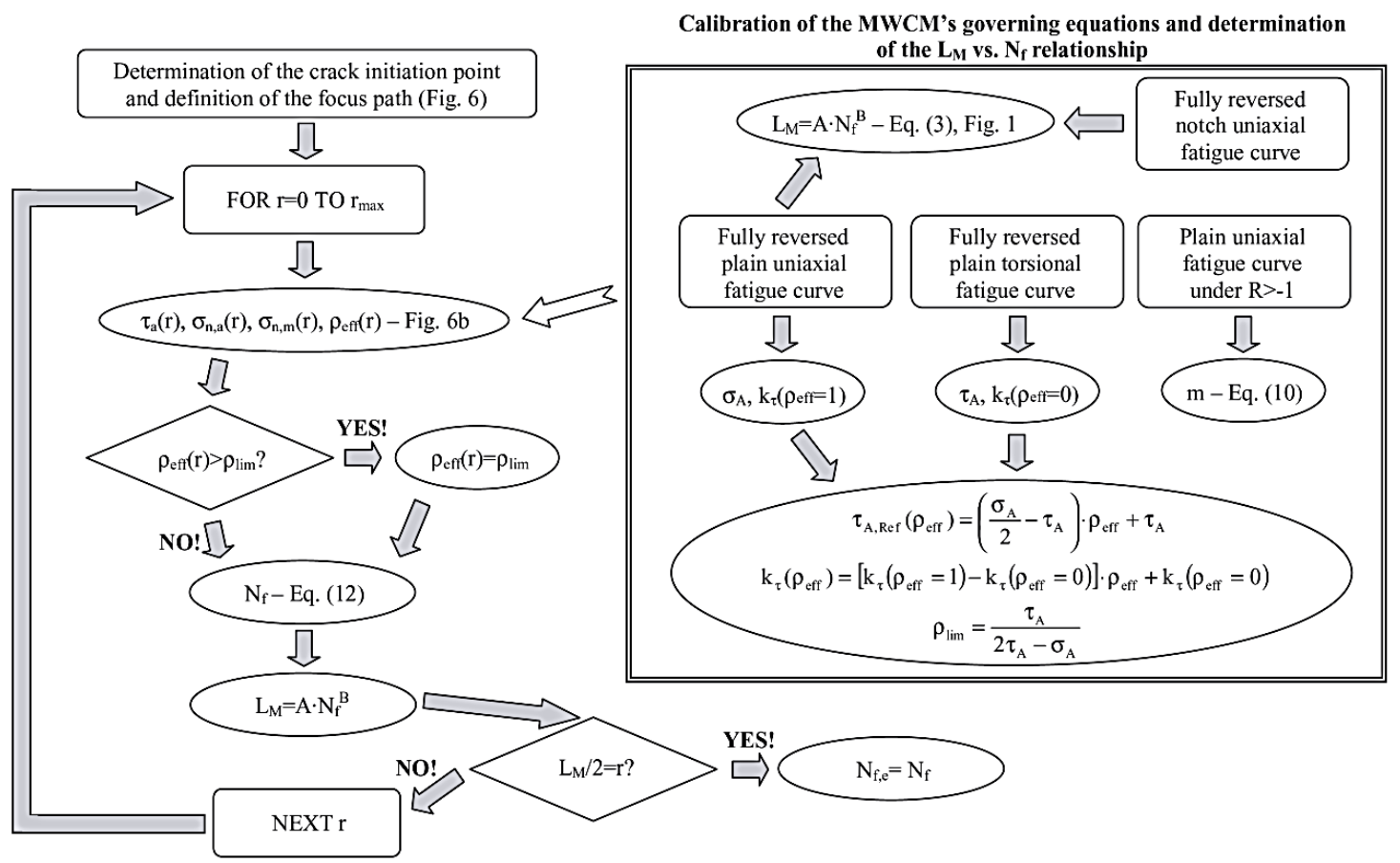

Figure 3. Flow-chart summarizing the in-field use of the MWCM method.

\section{Endurance Function Model}

(Brighenti et al., 2006) proposed an endurance function model on the basis of a continuum damage mechanics approach, with the assumption that the whole fatigue life is crack nucleation dominated and the fatigue life for crack propagation is negligible with respect to total life (Ottosen et al., 2008). For isotropic materials, the endurance function can be expressed as Eq. (4):

$$
E\left(\sigma, S_{e}\right)=\left[a_{1} \cdot I_{1}(\sigma)+a_{2} \cdot I_{2}^{1 / 2}(\sigma)+a_{3} \cdot I_{3}^{1 / 3}(\sigma)+a_{4} \cdot J_{2}^{1 / 2}\left(S_{e}\right)+a_{5} \cdot J_{3}^{1 / 3}\left(S_{e}\right)\right]-\sigma_{0}=0
$$


where, $a_{1}$ to $a_{5}$ and $\sigma_{0}$ are the material constants, $I_{1}, I_{2}, I_{3}$ are stress tensor invariants and $J_{2}, J_{3}$ deviatoric stress invariants are functions of stress tensor $\sigma$ and effective deviatoric stress tensor $S_{e}$ respectively. Here $S_{e}=S-S_{b}$, i.e., $S$ is the current applied deviatoric stress tensor and $S_{b}$ is the back stress tensor which measures the endurance function evolution in the stress space. A genetic algorithm (GA) is used to find the optimum values of these parameters. In order to apply the endurance function model, values of model parameters need to be evaluated, as defined in the equation.

The steel alloy C40 specimen (Figure 1) is tested against in-phase and out-ofphase loading conditions published in the literature (Table 1), first by using MWCM with the TCD and MVM techniques, and secondly with the endurance function model. For implementing the MCWM method shown in Figure 3 in ANSYS, an algorithm is developed using Ansys Parametric Design Language (APDL). The algorithm identifies the critical plane using the MVM method by first identifying planes with maximum variance in shear stress, and then selecting from these the plane with maximum $\rho_{\text {eff }}$. Normal stress $\sigma_{n, a}(r)$ with respect to the critical plane and shear stress in the maximum variance direction $\tau_{a}(r)$ on the critical plane are calculated. The fatigue life value is calculated using the normal and shear stress (Eq. 2) and the calculated fatigue life $N_{f}$ is used to calculate critical length $L_{M}$ (Eq. 3). The critical length value is compared with the distance " $r$ " of the assumed critical point from the component surface (according to the TCD hypothesis) and iterations continue until critical length $L_{M}$ becomes equal to the distance of the critical point. And the fatigue life at this point is reported as the fatigue life of the component where the crack is initiated.

Table 2. Predicted fatigue life of C40 steel.

\begin{tabular}{|c|c|c|c|c|}
\hline \multicolumn{2}{|c|}{ Load (MPa) } & \multirow{3}{*}{$\begin{array}{l}\text { Experimental cycles } \\
\text { to failure }\left(\mathrm{N}_{\mathrm{f}}\right) \times 10^{6}\end{array}$} & \multirow{2}{*}{\multicolumn{2}{|c|}{$\begin{array}{l}\text { Predicted cycles to failure } \\
\qquad\left(\mathrm{N}_{\mathrm{p}}\right) \times 10^{6}\end{array}$}} \\
\hline \multirow[t]{2}{*}{$\begin{array}{c}\text { Normal stress } \\
\sigma(\mathrm{MPa}) \\
\end{array}$} & \multirow[t]{2}{*}{$\begin{array}{c}\text { Shear stress } \\
\tau(\mathrm{MPa})\end{array}$} & & & \\
\hline & & & $\begin{array}{l}\text { MCWM- } \\
\text { MVM }\end{array}$ & $\begin{array}{c}\text { Endurance } \\
\text { function }\end{array}$ \\
\hline \multicolumn{5}{|c|}{ For $\mathrm{R}=-1$ and phase $=0$} \\
\hline 200.00 & 200.00 & 0.027 & 0.021 & 0.027 \\
\hline 179.00 & 179.00 & 0.22 & 0.038 & 0.032 \\
\hline 160.00 & 160.00 & 0.072 & 0.079 & 0.045 \\
\hline 129.75 & 129.75 & 0.18 & 0.22 & 0.110 \\
\hline 118.80 & 118.80 & 0.44 & 0.44 & 0.180 \\
\hline 101.00 & 101.00 & 2.0 & 0.86 & 1.750 \\
\hline \multicolumn{5}{|c|}{ For $\mathrm{R}=-1$ and phase $=90$} \\
\hline 199.70 & 199.70 & 0.011 & 0.105 & 0.0092 \\
\hline 180.00 & 180.00 & 0.018 & 0.187 & 0.0140 \\
\hline 160.25 & 160.25 & 0.047 & 0.520 & 0.0230 \\
\hline 140.00 & 140.00 & 0.280 & 0.850 & 0.0510 \\
\hline 129.65 & 129.65 & 0.690 & 1.500 & 0.0690 \\
\hline 99.60 & 99.60 & 2.000 & 3.698 & 1.2000 \\
\hline
\end{tabular}

The endurance function is implemented using FEA to calculate the principal stresses at the critical point on the notch root surface of the specimen. Then stress invariants are calculated and used with the endurance function Eq. (4) and the GA tool 
to estimate the coefficients of the endurance function to estimate the fatigue life. Results from experimental fatigue life values from the literature (Table 1 (Atzori et al., 2006)) and the predictions made by the two fatigue models under consideration are reported side by side in Table 2. The results show that the MWCM method is overestimating fatigue life at higher loads but with a small margin, while the endurance function model predicted conservative values at the same loads with the same accuracy. In out-of-phase conditions, the MWCM overestimated the life with a considerable margin, resulting in highly non-conservative fatigue life estimates, except for one or two instances where the values are close to the experimental fatigue life value; but the endurance function model estimated the life with greater accuracy and on the conservative side at every applied out-of-phase loading condition. From the results and the above arguments, it can be deduced that both models can predict fatigue life in the case of in-phase loads with good accuracy, but the MWCM method shows non-conservative fatigue life estimates in outof-phase regions. This may be because the MWCM method requires careful calibration of model equations, which is a difficult task (Susmel \& Taylor, 2008). But in the case of the endurance function model, application of the GA makes it very flexible for adaptation to different conditions.

\section{CONCLUSIONS}

The MWCM method in conjunction with the TCD and MVM techniques and endurance function model were studied with steel alloy C40 for in-phase and out-of-phase loading conditions. The results show that the endurance function model predicted the fatigue life with good accuracy with respect to the experimental fatigue life in both types of load cases. The MWCM method estimated life with good agreement in the in-phase loading case, but gave higher fatigue lives in the out-of-phase loading case than the experimental values. Overall, both models performed well in estimating fatigue lives and a more careful study is needed of the MWCM method to better understand its behavior in multiaxial loading conditions. And more detailed study is needed of the endurance function model to monitor its performance in complex loading conditions.

\section{ACKNOWLEDGMENTS}

The authors would like to thank Universiti Malaysia Pahang for financial support under project no. RDU110332 and providing laboratory facilities.

\section{REFERENCES}

Abdullah, S., Al-Asady, N. A., Ariffin, A. K., \& Rahman, M. M. (2008). A review on finite element analysis approaches in durability assessment of automotive components. Journal of Applied Sciences, 8(2), 2192-2201.

Abdullah, S., Beden, S. M., Ariffin, A. K., \& Rahman, M. M. (2008). Fatigue life assessment for metallic structure: A case study of shell structure under variable amplitude loading Journal of Applied Sciences, 8, 1622-1631.

Al-Asady, N. A., Abdullah, S., Ariffin, A. K., Bedan, S. M., \& Rahman, M. M. (2009). Comparison between experimental road data and finite element analysis data for automotive lower suspension arm. European Journal of Scientific Research, 29(4), 557-571. 
Ali, N., Mustapa, M. S., Ghazali, M. I., Sujitno, T., \& Ridha, M. (2013). Fatigue life prediction of commercially pure titanium after nitrogen ion implantation. International Journal of Automotive and Mechanical Engineering, 7, 10051013.

Atzori, B., Berto, F., Lazzarin, P., \& Quaresimin, M. (2006). Multi-axial fatigue behaviour of a severely notched carbon steel. International Journal of Fatigue, $28,485-493$.

Bedan, S. M., Abdullah, S., Ariffin, A. K., Al-Asady, N. A., \& Rahman, M. M. (2008). Fatigue life assessment of different steel-based shell materials under variable amplitude loading. European Journal of Scientific Research, 29(1), 157-169.

Borlea, A., Rusu, T., Ionescu, S., Cretu, M., \& Ionescu, A. (2011). Acoustical materialssound absorbing materials made of pine sawdust. Romanian Journal of Acoustical and Vibration, 8(2), 95-98.

Brighenti, R., Carpinteri, A., \& Vantadori, S. (2006). A genetic algorithm applied to optimisation of patch repairs for cracked plates. Computer Methods in Applied Mechanics and Engineering, 196, 466-475.

Domínguez Almaraz, G. M., Guzmán Tapia, M., Tapia Silva, E. E., \& Cadenas Calderón, E. (2010). Fatigue life prediction based on macroscopic plastic zone on fracture surface of aisi-sae 1018 steel. International Journal of Automotive and Mechanical Engineering, 1, 29-37.

Hariharan, K., Prakash, R. V., \& Prasad, M. S. (2011). Weighted error criterion to evaluate strain-fatigue life prediction methods. International Journal of Fatigue, 33, 727-734.

Kamal, M., Rahman, M. M., \& Rahman, A. G. A. (2012). Fatigue life evaluation of suspension knuckle using multibody simulation technique. Journal of Mechanical Engineering and Sciences, 3, 291-300.

Kamal, M., Rahman, M. M., \& Sani, M. S. M. (2013). Application of multibody simulation for fatigue life estimation. International Journal of Automotive and Mechanical Engineering, 7, 912-923.

Lagoda, T., Macha, E., \& Bedkowski, W. (1999). A critical plane approach based on energy concepts: Application to biaxial random tension-compression high-cycle fatigue regime. International Journal of Fatigue, 21(5), 431-443.

Laurens, N., Koolwijk, P., \& De Maat, M. P. M. (2006). Fibrin structure and wound healing. Journal of Thrombosis and Haemostasis, 4(5), 932-939.

Macha, E., \& Niesłony, A. (2007). Spectral method in multiaxial random fatigue: Springer-Verlag Berlin Heidelberg.

Meggiolaro, M. A., \& de Castro, J. T. P. (2012). An improved multiaxial rainflow algorithm for non-proportional stress or strain histories - part ii: The modified wang-brown method. International Journal of Fatigue, 42, 194-206.

Ottosen, N. S., Stenstrom, R., \& Ristinmaa, M. (2008). Continuum approach to highcycle fatigue modeling. International Journal of Fatigue, 30, 996-1006.

Papuga, J. (2011). A survey on evaluating the fatigue limit under multiaxial loading. International Journal of Fatigue, 33, 153-165.

Rahman, M. M., Ariffin, A. K., Abdullah, S., Noor, M. M., \& Bakar, R. A. (2009a). Durability assessment of cylinder block for two-stroke free piston linear engine using random loading. American Journal of Applied Sciences, 6(4), 726-735.

Rahman, M. M., Ariffin, A. K., Abdullah, S., Noor, M. M., Bakar, R. A., \& Maleque, M. A. (2008). Finite element based fatigue life prediction of cylinder head for 
two-stroke linear engine using stress-life approach. Journal of Applied Sciences, 8(19), 3316-3327.

Rahman, M. M., Ariffin, A. K., Jamaludin, N., \& Haron, C. H. C. (2005). Vibration fatigue analysis of cylinder head of a new two-stroke free piston engine using finite element approach. Structural Integrity and Durability, 1(2), 121-129.

Rahman, M. M., Ariffin, A. K., Jamaludin, N., \& Haron, C. H. C. (2006). Influence of surface treatments on fatigue life of a free piston linear generator engine component using random loading. Journal of Zhejiang University of Science Part A, 7(11), 1819-1830.

Rahman, M. M., Ariffin, A. K., Jamaludin, N., \& Haron, C. H. C. (2007). Finite element based durability assessment of a free piston linear engine component. Journal of Structural Durability and Health Monitoring, 3(1), 1-13.

Rahman, M. M., Ariffin, A. K., Rejab, M. R. M., Kadirgama, K., \& Noor, M. M. (2009b). Multiaxial fatigue behavior of cylinder head for a free piston linear engine. Journal of Applied Sciences, 9(15), 2725-2734.

Rahman, M. M., Ariffin, A. K., Rejab, M. R. M., Kadirgama, K., \& Noor, M. M. (2009c). Multiaxial fatigue behaviour of cylinder head for a free piston linear engine. Journal of Applied Sciences, 9(15), 2725-2734.

Rahman, M. M., Kadirgama, K., Noor, M. M., Rejab, M. R. M., \& Kesulai, S. A. (2009d). Fatigue life prediction of lower suspension arm using strain-life approach. European Journal of Scientific Research, 30(3), 437-450.

Rahman, M. M., Noor, M. M., Kadirgama, K., Maleque, M. A., \& Bakar, R. A. (2011). Modeling, analysis and fatigue life prediction of lower suspension arm. Advanced Materials Research, 264-265, 1557-1562.

Stephens, R. I., Fatemi, A., Stephens, R. R., \& Fuchs, H. O. (2000). Metal fatigue in engineering: New York: John Wiley and Sons.

Susmel, L. (2010). A simple and efficient numerical algorithm to determine the orientation of the critical plane in multiaxial fatigue problems. International Journal of Fatigue, 32, 1875-1883.

Susmel, L., \& Taylor, D. (2008). The modified wöhler curve method applied along with the theory of critical distances to estimate finite life of notched components subjected to complex multiaxial loading paths. Fatigue and Fracture of Engineering Materials and Structures, 31, 1047-1010. 